\title{
Article \\ FEM Analysis of Various Multilayer Structures for CMOS Compatible Wearable Acousto-Optic Devices
}

\author{
Mehwish Hanif ${ }^{1, *}$, Varun Jeoti ${ }^{2}$, Mohamad Radzi Ahmad ${ }^{1}\left({ }^{1}\right.$, Muhammad Zubair Aslam ${ }^{1}$, Saima Qureshi $^{2}$ \\ and Goran Stojanovic ${ }^{2}$ (D) \\ 1 Department of Electrical and Electronics Engineering, Universiti Teknologi PETRONAS, \\ Seri Iskandar 32610, Perak, Malaysia; mohamadradzi.ahmad@utp.edu.my (M.R.A.); \\ m.zubair_g02974@utp.edu.my (M.Z.A.) \\ 2 Faculty of Technical Sciences, University of Novi Sad, Trg Dositeja Obradovica 6, 21000 Novi Sad, Serbia; \\ varunjeoti@uns.ac.rs (V.J.); saima.qureshi@uns.ac.rs (S.Q.); sgoran@uns.ac.rs (G.S.) \\ * Correspondence: mehwish_16005841@utp.edu.my; Tel.: +60-146-605-693
}

check for updates

Citation: Hanif, M.; Jeoti, V.; Ahmad, M.R.; Aslam, M.Z.; Qureshi, S.; Stojanovic, G. FEM Analysis of Various Multilayer Structures for CMOS Compatible Wearable Acousto-Optic Devices. Sensors 2021, 21, 7863. https://doi.org/10.3390/ s21237863

Academic Editors: Hugo Aguas and Matteo Tonezzer

Received: 16 October 2021

Accepted: 22 November 2021

Published: 26 November 2021

Publisher's Note: MDPI stays neutral with regard to jurisdictional claims in published maps and institutional affiliations.

Copyright: (c) 2021 by the authors. Licensee MDPI, Basel, Switzerland. This article is an open access article distributed under the terms and conditions of the Creative Commons Attribution (CC BY) license (https:// creativecommons.org/licenses/by/ $4.0 /)$.

\begin{abstract}
Lately, wearable applications featuring photonic on-chip sensors are on the rise. Among many ways of controlling and/or modulating, the acousto-optic technique is seen to be a popular technique. This paper undertakes the study of different multilayer structures that can be fabricated for realizing an acousto-optic device, the objective being to obtain a high acousto-optic figure of merit (AOFM). By varying the thicknesses of the layers of these materials, several properties are discussed. The study shows that the multilayer thin film structure-based devices can give a high value of electromechanical coupling coefficient $\left(k^{2}\right)$ and a high AOFM as compared to the bulk piezoelectric/optical materials. The study is conducted to find the optimal normalised thickness of the multilayer structures with a material possessing the best optical and piezoelectric properties for fabricating acousto-optic devices. Based on simulations and studies of SAW propagation characteristics such as the electromechanical coupling coefficient $\left(k^{2}\right)$ and phase velocity $(v)$, the acousto-optic figure of merit is calculated. The maximum value of the acousto-optic figure of merit achieved is higher than the AOFM of all the individual materials used in these layer structures. The suggested SAW device has potential application in wearable and small footprint acousto-optic devices and gives better results than those made with bulk piezoelectric materials.
\end{abstract}

Keywords: figure of merit; acousto-optic; $\mathrm{SAW} ; \mathrm{LiNbO}_{3} ; \mathrm{ZnO} ; \mathrm{AlN} ; \mathrm{SiO}_{2} ;$ multilayer structures; piezoelectric; optics; COMSOL; FEM

\section{Introduction}

In the last few decades, photonic on-chip sensors have gained significant attention amongst the various attractive photonic integrated circuits (PICs) applications [1-4]. Moreover, due to the advancement in optic structures (gratings, waveguides, etc.), photonicsbased sensors have also gained considerable interest in several other fields like telecommunication and bio-medical instrumentation [5]. In the area of integrated optics, surface acousto-optic (AO) devices such as tunable optical filters, modulators, and optical switches are extensively used [6-8]. As the demand for $\mathrm{AO}$ devices increases, the interest in using AO material with high sensitivity towards acoustic or optic stimulants also increases.

The application of acousto-optic tunable filters (AOTFs) in spectroscopy has been well recognised in the past several years. Spectrometers based on AOTF technology have several appealing design characteristics. Among these advantages, the most prominent ones are high spectral resolution, less rf driving power, high durability, compact size, maintenancefree functioning, lightweight and quick data gathering [9]. Another important feature of AOTFs is, that they can simultaneously and individually filter a wide range of optical wavelengths by operating the acoustic transducer at various corresponding frequencies. They are thus suited for use in spectrometer instruments as the tuning element. A schematic 
of a typical miniaturized AOTF spectrometer is shown in Figure 1. In the past few years, efforts have been made to incorporate spectrometers in wearable sensors. AOTF-based spectrometers possess the potential to be incorporated into such sensors [10]. However, to design such a device the features and design parameters (acousto-optic) of an AOTF must be taken into consideration. As they play a vital role in the miniaturization of the device [11].

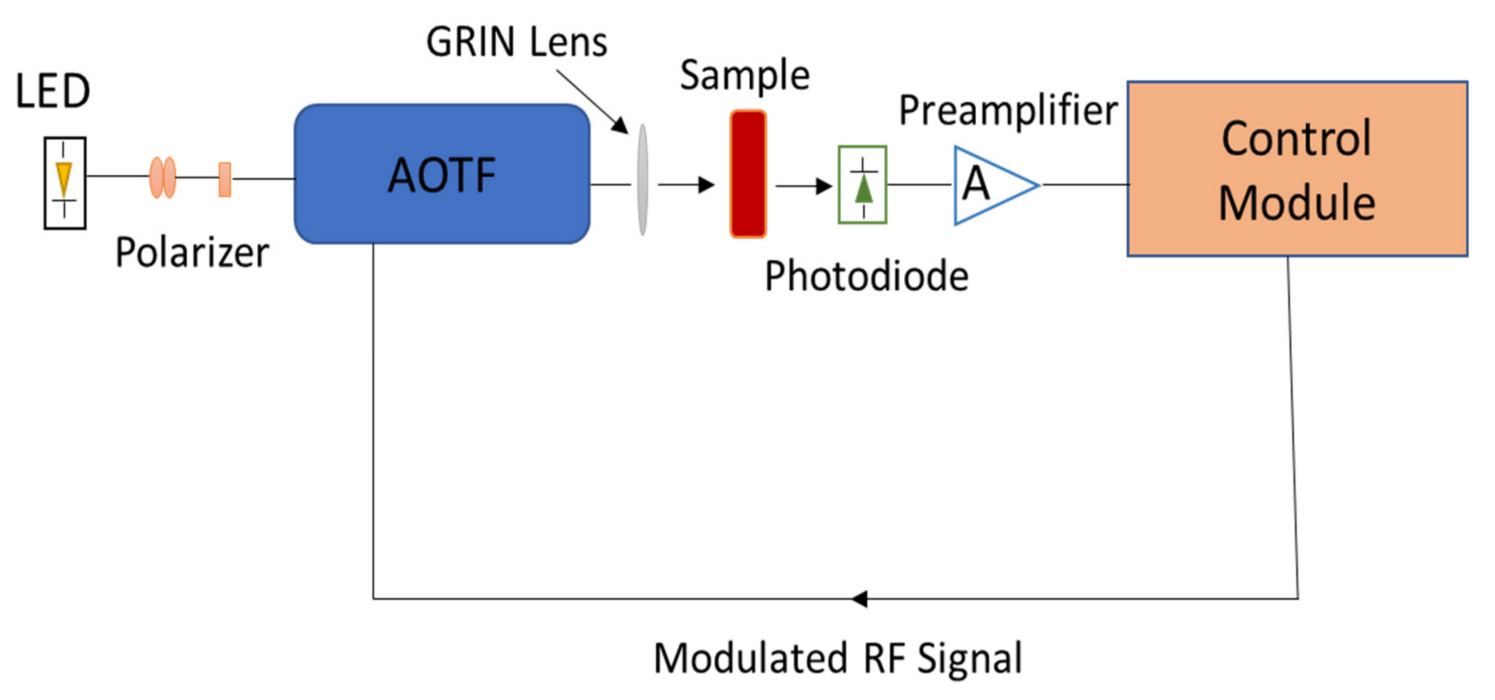

Figure 1. A schematic of the experimental setup of an AOTF-based spectrometer.

Previously, acousto-optic parameters were primarily investigated in the domain of crystallography; however, the focus has now switched to device optimisation [12]. Most of the photonics-based sensors work on the principle of acousto-optic effect in which there is a surface acoustic wave (SAW) device that acts as piezoelectric and optic devices. The most attractive features of SAW devices are that they consume less power and have a fast response time. So far, typical piezoelectric materials utilised in acousto-optic devices are langasite $\left(\mathrm{La}_{3} \mathrm{Ga}_{5} \mathrm{SiO}_{14}\right)$, lead molybdate $\left(\mathrm{PbMoO}_{4}\right)$, quartz $\left(\mathrm{SiO}_{2}\right)$, tellurium dioxide $\left(\mathrm{TeO}_{2}\right)$, lithium tantalite $\left(\mathrm{LiTaO}_{3}\right)$,) and lithium niobate $\left(\mathrm{LiNbO}_{3}\right)$ [4]. These bulk piezoelectric materials are used in most acoustic devices, but they are generally expensive and difficult to integrate with electronics, and some are even toxic in nature. Moreover, they are usually delicate and fragile if polished into extremely thin structures for high-frequency applications. In addition to this, using these large bulk materials is impractical in terms of cost, size, acousto-optic figure of merit, and integration [13]. The optimum thickness of the substrate required for SAW applications is normally around $10 \lambda$ or more. This thickness is chosen so that all the SAW travel on the top surface (piezoelectric material) and eventually dies out when it travels deeper into the substrate. However, for acousto-optic purposes where SAW interacts with light over an optical waveguide, the waveguide thickness can be of the order of 1 or more wavelengths of the infrared maximum range-nearly 5 microns or less. Hence, the multilayer substrate thickness is expected to be in excess of $10 \mathrm{~s}$ of the wavelength while the optical waveguide thickness can be about 1 wavelength or so. Attempts to replace these bulk materials with thin films have produced promising results [14]. Here, we emphasise the need to evaluate and optimise these thin film structures for achieving a better acousto-optic figure of merit.

\section{Literature Review}

The use of thin film-based optical devices [15-18] has increased recently due to the advancement of thin-film deposition technology that can produce thin films with high uniformity, homogeneity, etc. These devices typically use single-layer thin films and can achieve remarkable performance. However, the performance of these devices can be further improved by considering alternative thin films that have been made available recently [19]. 
Using these thin films in a multilayer structure can significantly enhance the device's performance. For instance, in designing optical filters or SAW devices, multilayer structures improve phase velocity, temperature stability, and mechanical strength [20-22]. In addition to this, the use of multilayer thin films is also preferable for broad tunability compared to the doped semiconductors, as these multilayer thin films give the desired response for various targeted applications. A typical example of it is an acousto-optic tunable filter (AOTF) [23-26]. The performance of devices utilising multilayered structures is dependent on various properties of a material medium such as acoustic, optic, and acousto-optic properties using both the sound and light wave interaction. For such devices to significantly improve the productivity of acousto-optic interaction, strong SAW interaction and optical waveguiding with low loss are essential. Thus, the determination of a reasonable layered structure is necessary. The layered structure utilised in most of the acousto-optic devices ought to have the characteristics such as high electromechanical coupling coefficient $\left(k^{2}\right)$ and phase velocity $(v)$ [27]. These parameters are then formulated into the acousto-optic figure of merit that can measure the suitability of such materials for AO devices.

The acousto-optic figure of merit measures a material's capacity to modulate diffraction intensity. For the effective realisation of such devices, it is better to make the blend of layer structure by utilising the materials having said properties [7,19]. Zinc oxide (ZnO) thin films exhibit good piezoelectric characteristics with high $k^{2}$, sensitivity, reliability and attractive optical properties. [28,29]. On account of promising optical, electro-optic, piezoelectric, photoelastic, photorefractive and elastic properties [30], ferroelectric lithium niobate $\left(\mathrm{LiNbO}_{3}\right)$ is also broadly utilised in guided-wave optics. Notwithstanding that, another component tends to be developed on various substrates, incorporating silicon (Si). Additionally, aluminium nitride (AlN)-based layered SAW has attracted significant interest [25-28]. It is mainly popular among other piezoelectric materials because of its high acoustic velocity $\left(5760 \mathrm{~ms}^{-1}\right)$. Another important feature of AlN thin film is its ease of integration into complementary metal-oxide-semiconductor (CMOS) platforms when contrasted with other piezoelectric materials like $\mathrm{LiNbO}_{3}, \mathrm{ZnO}, \mathrm{LiTaO}_{3}$ and quartz, as these materials create contamination in integrated circuit (IC) processes [31,32]. Within the last several years, there has been a tremendous rate of increase in interest in CMOS compatible surface acoustic wave (SAW) devices. The main reason to prefer CMOS compatible SAW devices over other devices is to eliminate the parasitic capacitance effect (mainly occurs when discrete SAW devices are integrated circuit connections are bonded). Furthermore, another reason is to minimise the footprints by merging the SAW device and the integrated circuit on a single chip.

In this manuscript, we investigated three multilayered structures $\mathrm{A}\left(\mathrm{ZnO} / \mathrm{SiO}_{2} / \mathrm{Si}\right)$, $\mathrm{B}\left(\mathrm{LiNbO}_{3} / \mathrm{SiO}_{2} / \mathrm{Si}\right)$, and $\mathrm{C}\left(\mathrm{AlN} / \mathrm{SiO}_{2} / \mathrm{Si}\right)$. There are three piezoelectric materials used in this study (i.e., $\mathrm{AlN}, \mathrm{ZnO}$, and $\mathrm{LiNbO}_{3}$ ). $\mathrm{AlN}$ and $\mathrm{ZnO}$ are in c-axis orientation with texture $11 \overline{20}$ and for $\mathrm{LiNbO}_{3}, 128^{\circ} \mathrm{Y}$-cut $\mathrm{Z}$-propagating is used. The top layers, i.e., $\mathrm{LiNbO}_{3}$, $\mathrm{AlN}, \mathrm{ZnO}$, are commonly used as bulk materials in AO devices with good piezoelectric and optic properties [20-23]. By comparing the propagation properties of SAW within said structures, the acousto-optic figure of merit of these three multilayer structures is then calculated.

\section{Materials and Methods}

This work uses the COMSOL Multiphysics software to perform 2D finite element method (FEM) simulations (modal and harmonic analysis) on the layered SAW device. Researchers used, validated, and reported on the results of the FEM study on different piezoelectric materials [33-36]. The complexity of modelling the SAW modes with longitudinal and shear vertical particle displacements can be significantly reduced using $2 \mathrm{D}$ structures. Furthermore, the use of an infinite set of IDTs helps in simulating a standing wave pattern that results when a resonator is employed. So, a unit cell with periodic boundary conditions on either side of the cell becomes a useful tool to simulate a SAW resonator with an infinite set of IDTs [32,37-40]. 
To determine the acousto-optic figure of merit, various SAW propagation characteristics, such as phase velocity and $k^{2}$, are calculated and used. The electromechanical coupling coefficient $\left(k^{2}\right)$ is a numerical measure of the conversion efficiency between electrical and acoustic energy in piezoelectric materials. In this study, all three structures work on the principle of the acousto-optic effect in which there is a surface acoustic wave (SAW) device that acts as a piezoelectric and optic device. In designing an efficient SAW-based acousto-optic device, one of the concerns is the driving power. The input driving power is directly related to the electromechanical coupling coefficient. Higher the $k^{2}$, lesser is the input power needed to convert the electrical energy to acoustic energy, which, as a result, enhances the device efficiency. Hence, the electromechanical coupling coefficient is the parameter that enables us to know the efficiency of the acousto-optic device. Additionally, the electromechanical coupling coefficient, which is a parameter that also depends on the piezoelectric film thickness, is also related to acoustic bandwidth. Higher bandwidth allows for a wider range of modulation for RF carrier, which, in turn, means a wider range of tunability of acousto-optic filters. Thus, this study analyses the FEM 2D models A, B, and $\mathrm{C}$ (Figure 2). Table 1 summarises the dimensions of the SAW device used in the simulation, while Figure 2 details the geometry of the 2D single-cell multilayered SAW device.

Table 1. Dimensions of the device.

\begin{tabular}{cc}
\hline Dimensions & Value $(\mu \mathrm{m})$ \\
\hline Wavelength & $4(\lambda)$ \\
Pitch of electrode & $2(\lambda / 2)$ \\
Width of IDT & $1(\lambda / 4)$ \\
Substrate thickness & $40(10 \lambda)$ \\
\hline
\end{tabular}

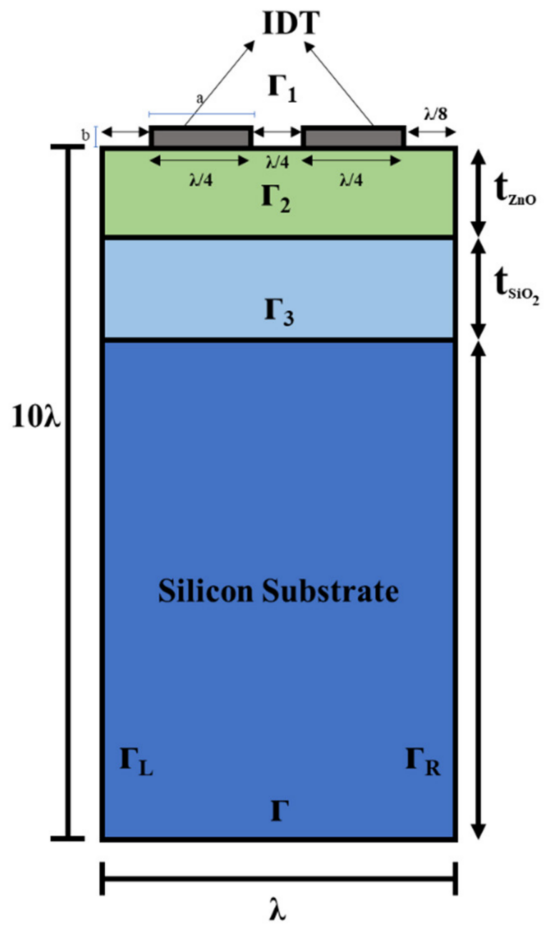

(a)

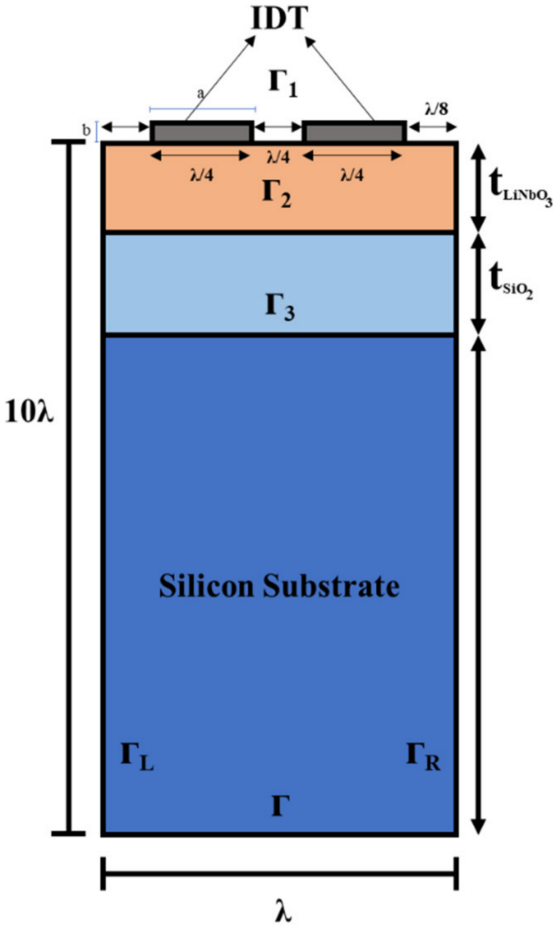

(b)

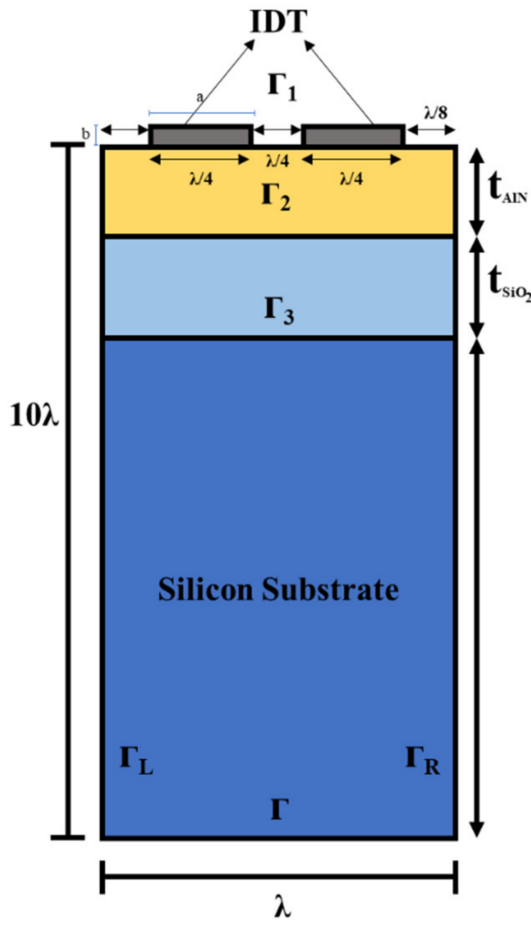

(c)

Figure 2. A two-dimensional unit cell geometry used in FEM simulation for the multilayer structure $(\mathbf{a})(\mathrm{ZnO} / \mathrm{SiO} 2 / \mathrm{Si})$, (b) $\left(\mathrm{LiNbO}_{3} / \mathrm{SiO}_{2} / \mathrm{Si}\right)$ and (c) $\left(\mathrm{AlN} / \mathrm{SiO}_{2} / \mathrm{Si}\right)$.

Hence, for simulating a SAW device, a single cell measuring one $\lambda$ is taken. A total of $10 \lambda$ is taken as the depth of a unit cell because SAW is generated on the top surface and dies out in the lower boundary as it travels down into the substrate. The material 
used for IDTs in this device is aluminium (Al). The properties of $\mathrm{Al}$ are obtained from the inbuilt COMSOL library, which is the density of 2700 kilogrammes per cubic metre, $70 \mathrm{GPa}$ Young's modulus, and a Poisson's ratio of 0.33 . The ratio of metallisation is taken as $50 \%$ $(2 a / \lambda)$, while $2.5 \%$ is the electrode's relative thickness $(b / \lambda)$. Here, the width and height of electrodes are $\mathrm{a}(\lambda / 4)$ and $\mathrm{b}(100 \mathrm{~nm})$, respectively. To improve the accuracy of the results, a very thin triangular mesh is used for the simulations. Both the electrodes, from the top and sides, are free in terms of mechanical boundaries. The boundaries of the left electrode are grounded, and for the right one, it is set to a floating potential with no charge accumulation on the surface. The boundary conditions utilised in the simulations are shown in Table 2, and the material constants used in the simulations are listed in Table 3. All the material constants mentioned in Table 3 are taken from reference [41-44].

Table 2. Boundary conditions (BC).

\begin{tabular}{ccc}
\hline & Mechanical BC & Electrical BC \\
\hline$\Gamma 1$ & Free & Zero Charge/Symmetry \\
$\Gamma 2$ & Continuity & Continuity \\
$\Gamma 3$ & Continuity & Continuity \\
$\Gamma$ & Fixed Constraint & Ground \\
$\Gamma \mathrm{L}, \Gamma \mathrm{R}$ & Periodic BC & - \\
\hline
\end{tabular}

Table 3. Constants of materials used ( $\mathrm{AlN}, \mathrm{LiNbO}_{3}, \mathrm{ZnO}, \mathrm{SiO}_{2}$ and $\left.\mathrm{Si}\right)$.

\begin{tabular}{|c|c|c|c|c|c|c|}
\hline Parameter & Symbol & AlN & $\mathrm{LiNbO}_{3}$ & $\mathrm{ZnO}$ & $\mathrm{SiO}_{2}$ & Si \\
\hline Density $\left(\mathrm{kg} / \mathrm{m}^{3}\right)$ & $\rho$ & 3260 & 4644 & 5606 & 2200 & 2330 \\
\hline \multirow{6}{*}{ Elastic constants (GPa) } & $c_{11}$ & 345 & 2.03 & 209.7 & 78.5 & 166 \\
\hline & $c_{12}$ & 125 & 0.53 & 12.1 & 16.1 & 64 \\
\hline & $\mathrm{c}_{13}$ & 120 & 0.75 & 105.4 & 16.1 & 64 \\
\hline & $c_{33}$ & 395 & 2.45 & 211.2 & 78.5 & 166 \\
\hline & $\mathrm{c}_{44}$ & 118 & 0.6 & 42.4 & 31.2 & 80 \\
\hline & $\mathrm{c}_{66}$ & 110 & - & - & 31.2 & 80 \\
\hline \multirow{3}{*}{ Piezoelectric constants $\left(\mathrm{C} / \mathrm{m}^{2}\right)$} & $\mathrm{e}_{15}$ & -0.48 & 4.1607 & -0.45 & - & - \\
\hline & $\mathrm{e}_{31}$ & -0.45 & 0.8661 & -0.51 & & \\
\hline & $\mathrm{e}_{33}$ & -1.55 & 3.7 & 1.22 & & \\
\hline \multirow{2}{*}{ Dielectric constants $\left(10^{-11} \mathrm{~F} / \mathrm{m}\right)$} & $\varepsilon_{11}$ & 9 & 43.6 & 8.55 & 3.32 & 10.62 \\
\hline & $\varepsilon_{33}$ & 11 & 29.16 & 10.2 & 3.32 & 10.62 \\
\hline Refractive index & $\mathrm{N}$ & 2.1 & 2.203 & 2.015 & 1.5 & 3.88 \\
\hline Acoustic velocity (m/s) & $v$ & 5760 & 6487.6 & 6133.5 & 3750 & 5000 \\
\hline Acousto-optic figure of merit $10^{-15}\left[\mathrm{~s}^{3} / \mathrm{kg}\right]$ & M2 & - & 10.418 & 2.572 & 0.59 & - \\
\hline
\end{tabular}

In general, the equation for determining the acoustic wave velocity is as follows:

$$
v=f \lambda
$$

The central frequency is denoted by $f$, and the wavelength of the acoustic wave is represented by $\lambda$. To find the velocity in eigenmode, the following equation is used:

$$
v=\left(f_{\text {res }}+f_{\text {anti }}\right) p
$$

Here, both $f_{\text {res }}$ and $f_{\text {anti }}$ frequencies denote the resonant and anti-resonant frequencies, respectively, and $p$ represents the pitch (electrode spacing + electrode width). In our study, the pitch value is $2 \mu \mathrm{m}(\lambda / 2)$, and the resonant and anti-resonant frequencies are eigenfrequencies we obtainthrough simulation analysis. The equation used to find $k$ is as follows:

$$
k^{2}=2\left(\frac{v-v_{m}}{v}\right)
$$


Where $v_{m}$ is the phase velocity with the metal short, and $v$ is the free surface velocity without it.

$\mathrm{ZnO}, \mathrm{LiNbO}_{3}$, and $\mathrm{AlN}$ thin films act as optic and piezoelectric layers in the proposed layer structure as shown in Figure $2 \mathrm{a}-\mathrm{c}$, respectively, with IDTs on top. The interaction of light and acoustic waves occurs on the top layer in all the structures. In all of these structures, a $\mathrm{SiO}_{2}$ layer is deposited on the silicon ( $\mathrm{Si}$ ) substrate. It is incorporatedbecause the index of refraction of $\mathrm{Si}$ is greater than the indexes of refraction of $\mathrm{ZnO}, \mathrm{LiNbO}_{3}$ and $\mathrm{AlN}$, whereas the index of refraction of $\mathrm{SiO}_{2}$ is less than the other materials deposited on top of it. Therefore, the waveguide action cannot be achieved without it [45]. Variation of the electric field in the IDTs, travelling in the top layer of all the structures, produces SAW and penetrates $\mathrm{SiO}_{2}$ from the top layer [46]. The light waves fall on the top layer (acting as the optic layer). It creates the acousto-optic effect after interaction with SAW, which is the basic concept of acousto-optic devices [47]. $\mathrm{ZnO}, \mathrm{LiNbO}_{3}$, and $\mathrm{AlN}$ are used in these structures because of their strong piezoelectric and optical characteristics, as well as the ease with which they are deposited [48-56]. A material's $k^{2}$ is dependent on characteristics such as dielectric, piezoelectric, and elastic properties. Therefore, the materials are selected based on these characteristics.

Furthermore, while choosing a material for the acousto-optic devices, it should have a suitable acousto-optic figure of merit, which is determined by the photoelastic constant $(p)$, density $(\rho)$, refractive index $(n)$, and acoustic phase velocity $(v)$. The acousto-optic figure of merit measures the suitability of a material to modulate the diffraction intensity. The acousto-optic figure of merit $(M)$ can be expressed mathematically as:

$$
M=\frac{n^{6} p^{2}}{\rho v^{3}}
$$

All the parameters in Equation (4) should be considered when selecting the top layer material. The refractive index and acoustic velocity are the most essential. The slower the acoustic and optical waves in the material, the more interaction is possible [57]. Some materials offer good optical properties like less losses and high transmittance, but the acousto-optic figure of merit becomes low because of having high acoustic velocity. There are other figures of merit related to acousto-optic devices; however, the acousto-optic figure of merit referred to in Equation (4) is used primarily for gauging the power efficiency of acousto-optic materials. It is preferable to use a combination of materials to achieve a high acousto-optic figure of merit. Therefore, to decrease the overall structure's velocity and increase the acousto-optic figure of merit, it is better to incorporate the structure with a material possessing low velocity. The velocity of the layer structure is the combined velocity of all the materials. With different combinations of these materials, the acousto-optic figure of merit is calculated.

\section{Results and Discussion}

To validate our FEM simulation method used in the structures under study, we first began by simulating the AlN/Diamond (slow-fast) structure, which was previously described [58]. In that study, the propagation characteristics of SAW were theoretically computed using PC acoustic wave software developed by McGill University. SAW propagation in multilayer structures is calculated with this software using the transfer matrix approach, which is implemented in this software. We obtained their numerical data by employing a semi-automated open-source plot digitiser application, i.e., WebPlotDigitizer v. 3.12, which has been utilised in several published papers. To conduct our investigation, we used the unit cell shown in Figure 2 (but with two layers, namely AlN/Diamond) and the boundary conditions shown in Table 2 to simulate the AlN/Diamond structure. The same material constants as those given were utilised [58]. Equations (1)-(3) are used to compute the SAW propagation characteristics. Figure 3 depicts the simulated results, which are somewhat similar to those presented in [58]. The slight inaccuracy can be attributed to the fact that the procedure employed in this case is different from the work presented in [58]. The 
approach utilised in [58] was based on a transfer matrix method that made assumptions about numerous thin layers' behaviour to approximate the behaviour of interfacial layers. In contrast, the method employed in this study is based on a finite element method (FEM).

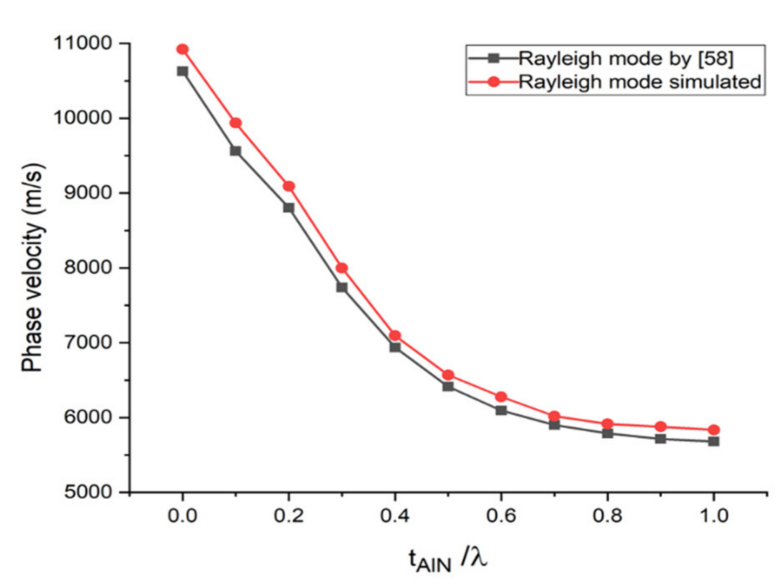

(a)

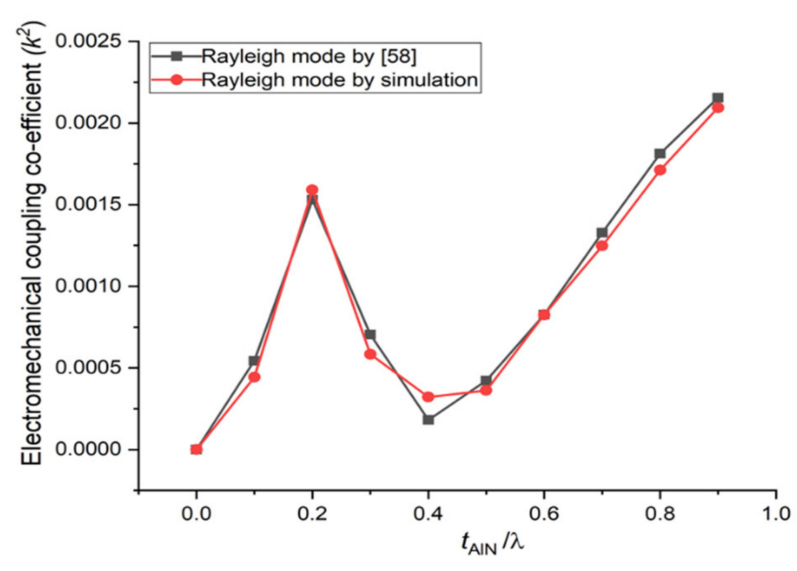

(b)

Figure 3. Simulated results of AlN/Diamond structure (a) phase velocity (Rayleigh mode) versus normalised thickness of AlN (b) $k^{2}$ (Rayleigh mode) versus normalised thickness of AlN.

A mesh convergence investigation was also carried out to justify the appropriateness of the chosen mesh density. The mesh density was increased until the SAW velocity values became constant. In this case, the most triangular mesh elements possible were selected (i.e., 120,503). However, increasing the number of mesh elements also increases the processing time. Therefore, to achieve accurate results, it has to be performed at the expense of processing time.

In this work, we calculated phase velocity and electromechanical coupling coefficient of structures $\mathrm{A}\left(\mathrm{ZnO} / \mathrm{SiO}_{2} / \mathrm{Si}\right), \mathrm{B}\left(\mathrm{LiNbO}_{3} / \mathrm{SiO}_{2} / \mathrm{Si}\right)$, and $\mathrm{C}\left(\mathrm{AlN} / \mathrm{SiO}_{2} / \mathrm{Si}\right)$ on different thicknesses of $\mathrm{SiO}_{2}(0.4 \mu \mathrm{m}, 1 \mu \mathrm{m}, 2 \mu \mathrm{m}$, and $3 \mu \mathrm{m})$ with changing thicknesses of $\mathrm{ZnO}$, $\mathrm{LiNbO}_{3}$ and $\mathrm{AlN}(0.4 \mu \mathrm{m}, 0.8 \mu \mathrm{m}, 1.6 \mu \mathrm{m}, 2.4 \mu \mathrm{m}, 3.2 \mu \mathrm{m}$ and $4 \mu \mathrm{m})$ using COMSOL. The values of resonant and anti-resonant frequencies are obtained using COMSOL. Afterward, using Equations (2) and (3) the SAW phase velocity and electromechanical coupling coefficient are calculated, respectively. The polarised mode studied in this work is the Rayleigh mode which occurs in the sagittal plane. The displacement profile for structures $\mathrm{A}\left(\mathrm{ZnO} / \mathrm{SiO}_{2} / \mathrm{Si}\right)$, $\mathrm{B}\left(\mathrm{LiNbO}_{3} / \mathrm{SiO}_{2} / \mathrm{Si}\right)$, and $\mathrm{C}\left(\mathrm{AlN} / \mathrm{SiO}_{2} / \mathrm{Si}\right)$ is shown in Figures $4-6$, respectively.

Figure 4 depicts the displacement profile of structure $\mathrm{A}\left(\mathrm{ZnO} / \mathrm{SiO}_{2} / \mathrm{Si}\right)$. Figure $4 \mathrm{a}-\mathrm{c}$ shows the displacement profile with the normalised thickness of $\mathrm{ZnO}$ as $0.01 \lambda, 0.1 \lambda$ and $2 \lambda$, respectively. It can be vividly seen that by increasing the thickness of $\mathrm{ZnO}$ that the surface acoustic waves start to confine in the $\mathrm{ZnO}$ layer. It can be seen from Figure $4 \mathrm{~b}$ that the whole wave is confined in $\mathrm{ZnO}$ and $\mathrm{SiO}_{2}$ layer and none of it is going in Silicon substrate.

Figure 5 shows the displacement profile of structure $\mathrm{B}\left(\mathrm{LiNbO}_{3} / \mathrm{SiO}_{2} / \mathrm{Si}\right)$. The shapes of the mode in the displacement profile help to identify the Rayleigh wave modes. Figure $5 \mathrm{a}-\mathrm{c}$ shows the results of Eigen frequency analysis for anti-resonance modes at $\mathrm{t}_{\mathrm{LiNbO} 3} / \lambda=0.01,0.1$, and 2 respectively. Moreover, it can be seen clearly from Figure $5 \mathrm{a}-\mathrm{c}$ that by increasing the thickness of the $\mathrm{LiNbO}_{3}$ layer, surface acoustic wave no longer travels in Silicon substrate. Additionally, if it keeps on increasing, it gets entirely confined only in the $\mathrm{LiNbO}_{3}$ layer.

Similarly, the displacement profile of structure $\mathrm{C}\left(\mathrm{AlN} / \mathrm{SiO}_{2} / \mathrm{Si}\right)$ is summarised in Figure 6. The displacement profile's mode shapes help in identifying Rayleigh wave modes. The results in Figure 6a-c were obtained using eigenfrequency analysis in anti-resonance modes for $\mathrm{t}_{\mathrm{AlN}} / \lambda=0.01,0.1$ and 2 . It can be seen that increasing the thickness of AlN thin film value of eigenfrequency increases and the surface acoustic wave no longer passes in Silicon substrate and only travels in $\mathrm{AlN}$ and $\mathrm{SiO}_{2}$ thin film, as shown in Figure 6b. It 
continues to do so as the thickness of the AlN layer increases until the entire acoustic wave is contained within the AlN substrate (as seen in Figure 6c). On this point, it reaches a velocity of $5507 \mathrm{~m} / \mathrm{s}$ at $\mathrm{t}_{\mathrm{AlN}} / \lambda=2$, which is close to AlN's theoretical acoustic velocity $(5600 \mathrm{~m} / \mathrm{s})[44]$.

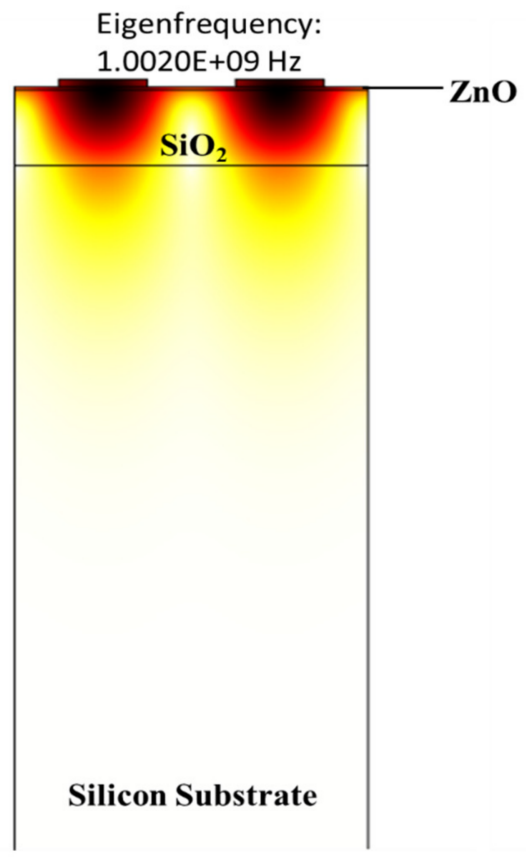

(a)

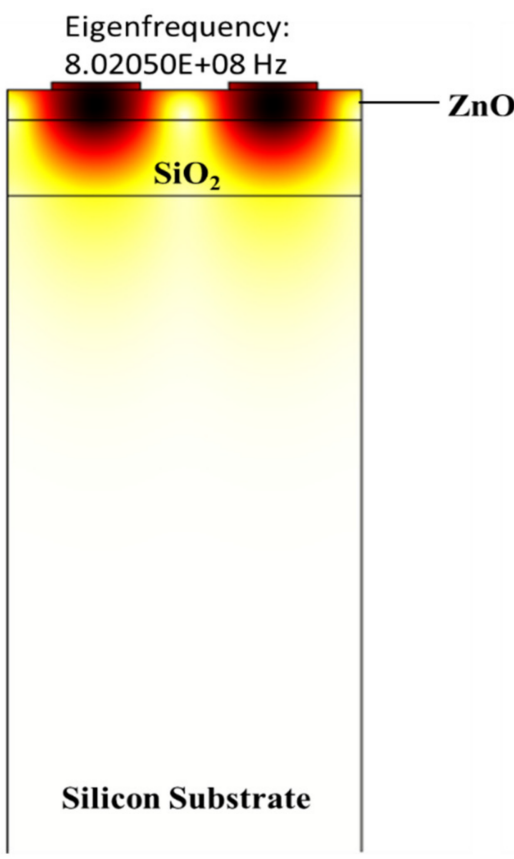

(b)

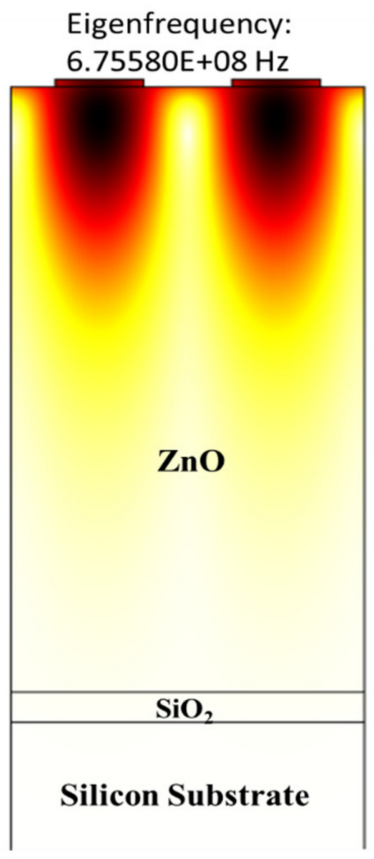

(c)

Figure 4. Zoom-in view of wave confinement and displacement profiles of structure $\mathrm{A}\left(\mathrm{ZnO} / \mathrm{SiO}{ }_{2} / \mathrm{Si}\right)$ in $\mathrm{Rayleigh}$ mode with the normalised thickness of $\mathrm{ZnO}$ (a) 0.01 , (b) 0.1 and (c) 2 .

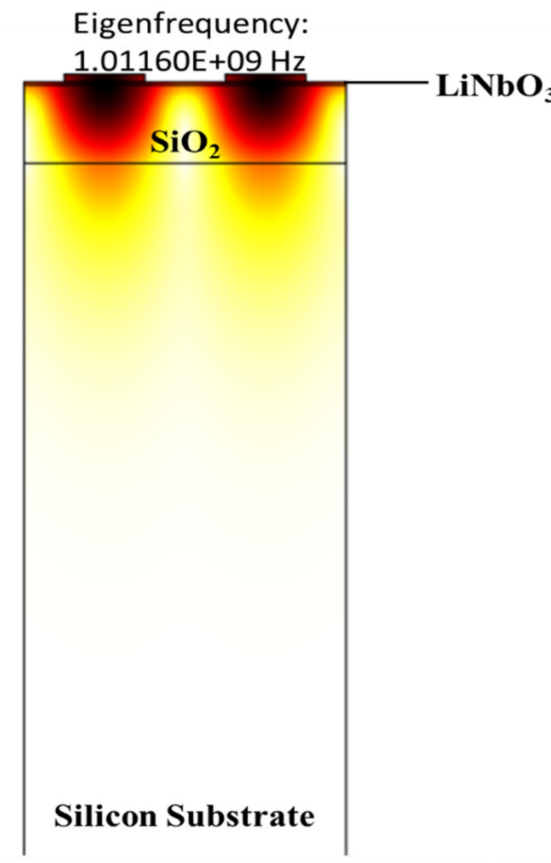

(a)

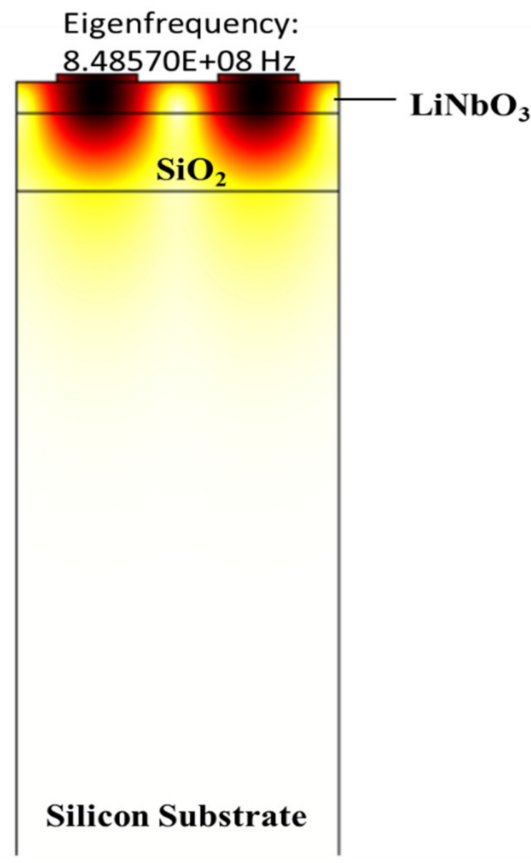

(b)

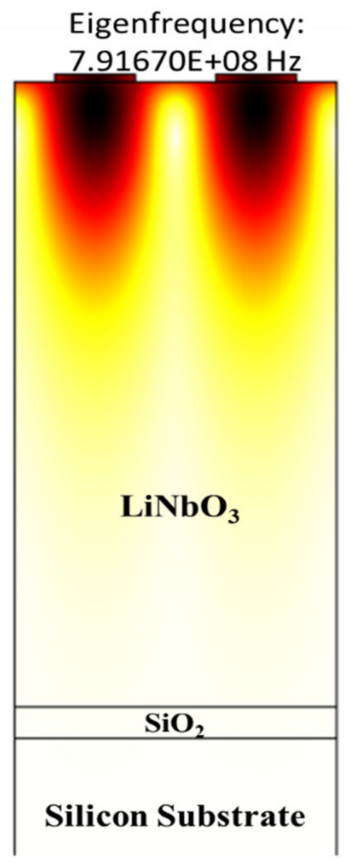

(c)

Figure 5. Zoom-in view of wave confinement and displacement profiles of structure $\mathrm{B}\left(\mathrm{LiNbO}_{3} / \mathrm{SiO}{ }_{2} / \mathrm{Si}\right)$ in Rayleigh mode with normalised thickness of $\mathrm{LiNbO}_{3}$ (a) 0.01 , (b) 0.1 and (c) 2 . 


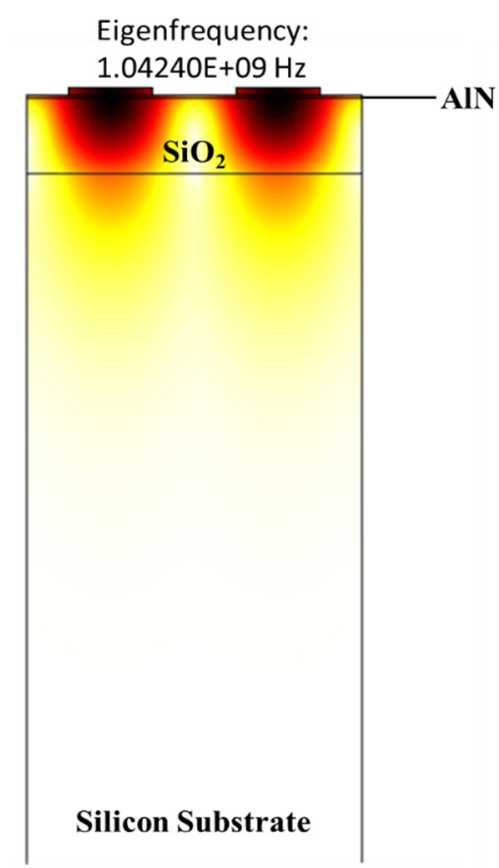

(a)

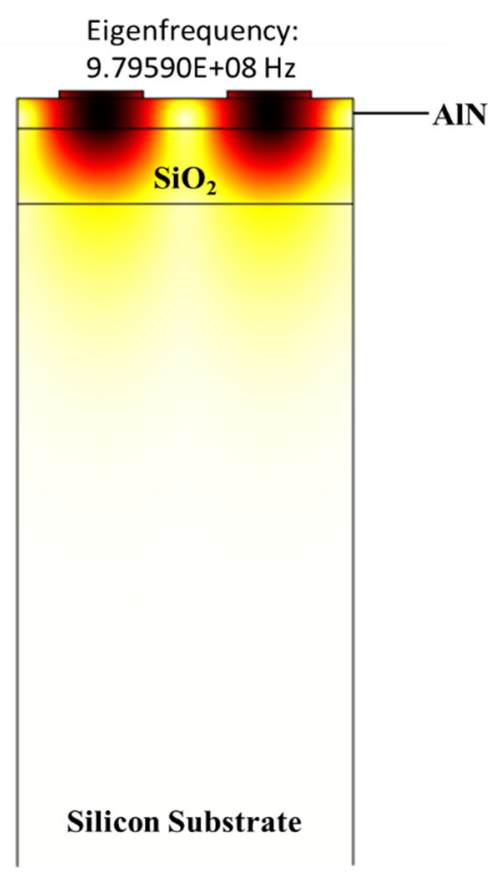

(b)

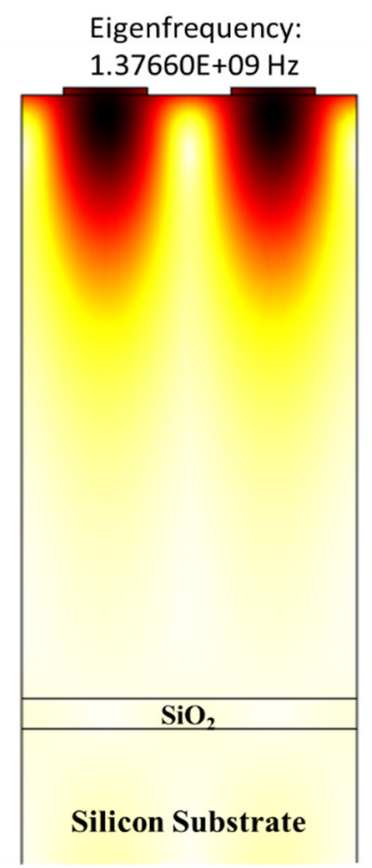

(c)

Figure 6. Zoom-in view of wave confinement and displacement profiles of structure $\mathrm{C}(\mathrm{AlN} / \mathrm{SiO} / \mathrm{Si})$ in $\mathrm{Rayleigh}$ mode with normalized thickness of AlN (a) 0.01 , (b) 0.1 and (c) 2 .

The simulation results for SAW propagation characteristics of the multilayer structures A, $B$ and $C$ are displayed in Figures 7 and 8. In this study, the normalised thickness chosen for $\mathrm{SiO}_{2}$ is $0.1 \lambda, 0.25 \lambda, 0.5 \lambda, 0.75 \lambda$ and $1 \lambda$. Whereas, $0.1 \lambda, 0.2 \lambda, 0.4 \lambda, 0.6 \lambda, 0.8 \lambda$ and $1.0 \lambda$ normalised thickness have been chosen in the case of $\mathrm{AlN}, \mathrm{ZnO}$ and $\mathrm{LiNbO}_{3}$.

It is clear from Figure 7 that the overall phase velocity decreases as the thickness of $\mathrm{SiO}_{2}$ increases. All three piezoelectric materials used in structures $\mathrm{A}, \mathrm{B}$ and $\mathrm{C}$ possess high acoustic velocities as compared to $\mathrm{SiO}_{2}$. The decrease in the overall behaviour of phase velocity in the structures $\mathrm{A}, \mathrm{B}$ and $\mathrm{C}$, due to the increase in the normalised thickness of $\mathrm{SiO}_{2}$ can be explained using the fact that there is a significant difference between the velocities of $\mathrm{SiO}_{2}(3750 \mathrm{~m} / \mathrm{s})$ with respect to the velocities of $\mathrm{AlN}(5760 \mathrm{~m} / \mathrm{s}), \mathrm{ZnO}(6133 \mathrm{~m} / \mathrm{s})$ and $\mathrm{LiNbO}_{3}(6487 \mathrm{~m} / \mathrm{s})$. However, if the change in the normalised thickness of AlN, $\mathrm{ZnO}$ and $\mathrm{LiNbO}_{3}$ is observed, the case is different. In the case of $\mathrm{AlN}$, when the thickness of AlN increases, the phase velocity also increases compared to the case when the thickness of $\mathrm{SiO}_{2}$ was increased. It happens because when the normalised thicknesses of AlN increases, the entire surface acoustic wave travels only in AlN layers, and none of them reaches the substrate. All surface acoustic waves become confined in the piezoelectric layer.

On the contrary, when the thickness of $\mathrm{ZnO}$ or $\mathrm{LiNbO}_{3}$ increases in structures $\mathrm{A}$ and B, as shown in Figure 7a,b, a declined trend is observed. However, by increasing the thickness by more than $0.2 \lambda$, there is no significant change in the behaviour of the phase velocity observed. It happens because the surface acoustic wave becomes confined in the top piezoelectric layer only.

Figure 8 shows the behaviour of the electromechanical coupling coefficient with respect to normalised thicknesses of $\mathrm{SiO}_{2}$ and the top layers in the structures $\mathrm{A}, \mathrm{B}$ and $\mathrm{C}$ (i.e., $\mathrm{ZnO}, \mathrm{LiNbO}_{3}$ and $\mathrm{AlN}$, respectively). The overall electromechanical coupling coefficient behaviour showed a decreasing trend with increased normalised thicknesses of $\mathrm{SiO}_{2}$. Figure $8 \mathrm{a}$ shows the change in the electromechanical coupling coefficient as $\mathrm{ZnO}^{\prime} \mathrm{s}$ thickness increases. It is observed that by increasing the normalised thickness of $\mathrm{ZnO}$, the electromechanical coupling coefficient decreased sharply. However, after the normalised value of 0.4 , no significant change in its value is observed. At the smaller values of the normalised thickness of $\mathrm{ZnO}\left(\mathrm{t}_{\mathrm{ZnO}} / \lambda=0.1\right.$ and 0.2$)$, surface acoustic waves 
are also travelling in $\mathrm{SiO}_{2}$. Whereas, when the normalised thickness is increased (greater than $\mathrm{t}_{\mathrm{ZnO}} / \lambda=0.2$ ), the surface acoustic waves become confined in $\mathrm{ZnO}$, due to which the electromechanical coupling coefficient becomes almost constant. Moreover, in all three structures, the highest value of $k^{2}$ is achieved at $0.4 \mu \mathrm{m}$ thickness of $\mathrm{SiO}_{2}$. Additionally, among all three structures, the highest value of electromechanical coupling coefficient is attained in structure $\mathrm{AlN} / \mathrm{SiO}_{2} / \mathrm{Si}$ (at $0.4 \mu \mathrm{m}$ thickness of $\mathrm{SiO}_{2}$ and $\mathrm{AlN}$ ), which is 7.15.

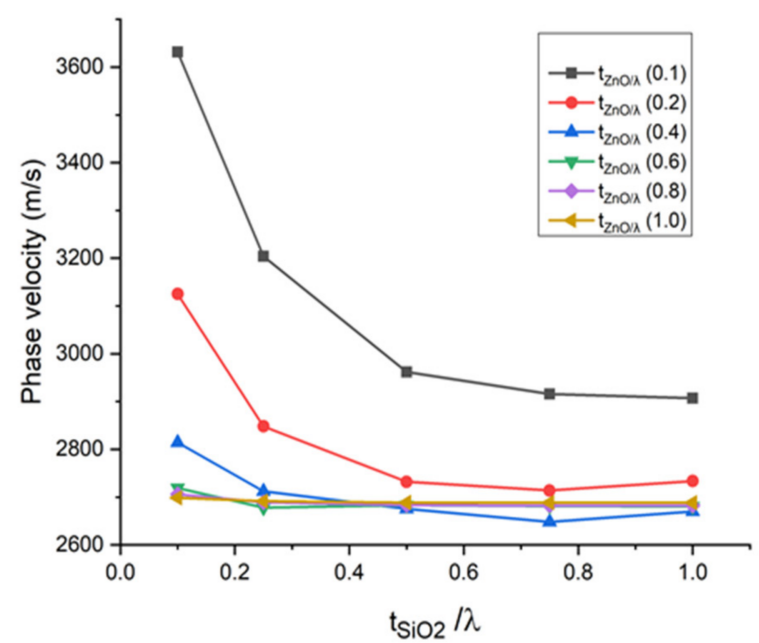

(a)

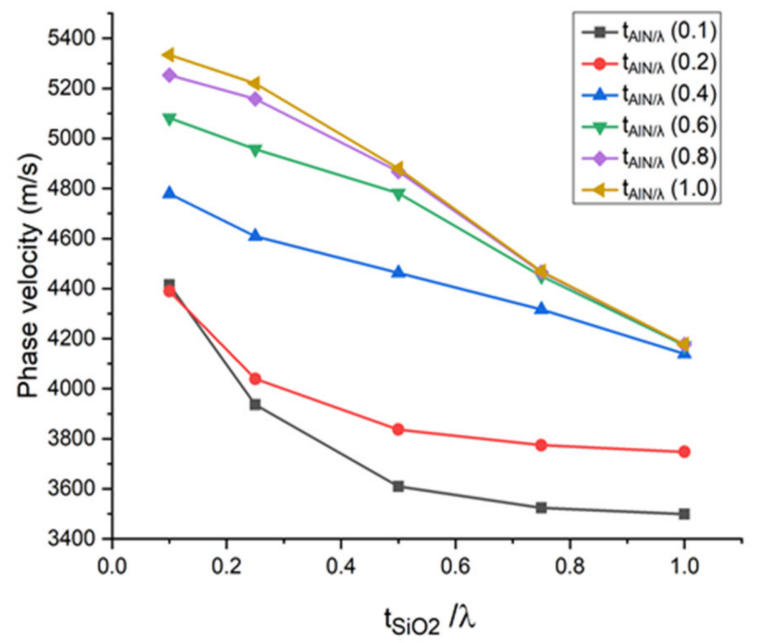

(c)

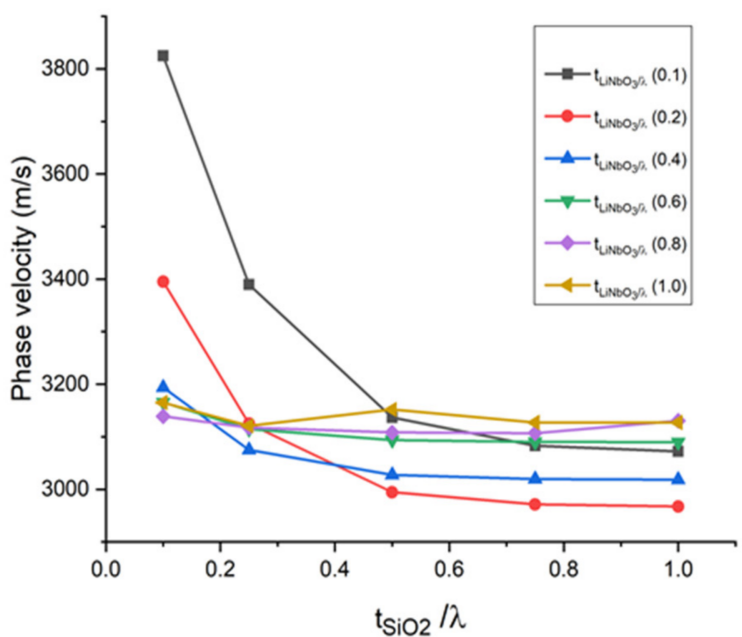

(b)

Figure 7. Phase velocity versus normalised thickness of $\mathrm{SiO}_{2}$ on different normalised thicknesses of (a) $\mathrm{ZnO}(\mathbf{b}) \mathrm{LiNbO}_{3}$ (c) AlN.

Table 4 illustrates the acousto-optic figure of merit, phase velocity, and electromechanical coupling coefficient of structures A, B, and C. It is evident from Table 4 that among all the structures, structure $\mathrm{C}\left(\mathrm{AlN} / \mathrm{SiO}_{2} / \mathrm{Si}\right)$ exhibits the highest value of electromechanical coupling coefficient (7.15 at the normalised thickness of $0.1 \lambda$ of $\mathrm{SiO}_{2}$ and $\mathrm{AlN}$ layer) with the acousto-optic figure of merit $7.04 \times 10^{-14} \mathrm{~s}^{3} / \mathrm{kg}$. Moreover, it is to be noted that the acousto-optic figure of merit achieved in structure $\mathrm{AlN} / \mathrm{SiO}_{2} / \mathrm{Si}$ with the thicknesses as mentioned earlier is higher than the acousto-optic figure of merit of all the individual materials used in these layer structures (i.e., $\mathrm{ZnO}, \mathrm{LiNbO}_{3}, \mathrm{AlN}$ and $\mathrm{SiO}_{2}$ ) $[29,49]$.

In light of the results discussed above, it can be concluded that to fabricate an acoustooptic device, structure $\mathrm{C}\left(\mathrm{AlN} / \mathrm{SiO}_{2} / \mathrm{Si}\right)$ would give promising results. However, there is a trade-off between normalised thickness, the acousto-optic figure of merit, acoustic velocity, and electromechanical coupling coefficient. Changing the value of normalised thicknesses, the above said properties could be tailored according to the requirements. Furthermore, 
AlN is well-suited for use in CMOS technologies since it can be readily deposited by physical vapour deposition at low temperatures, making it a cost-effective option $[59,60]$.

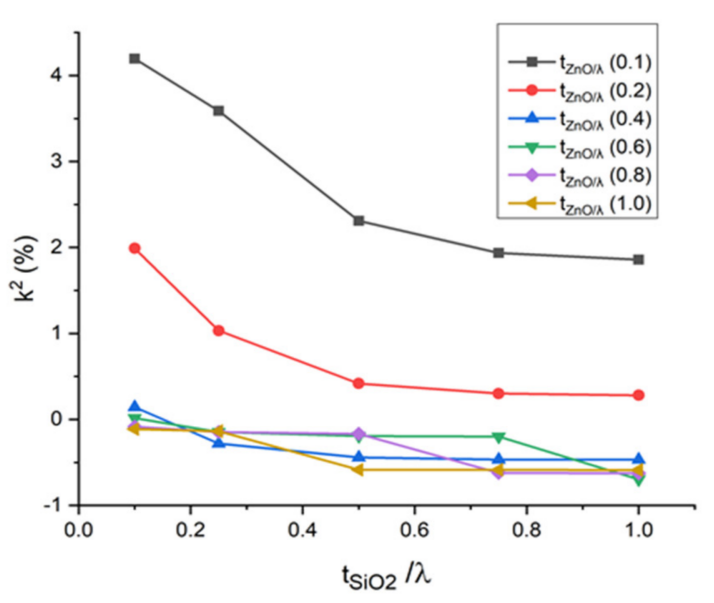

(a)

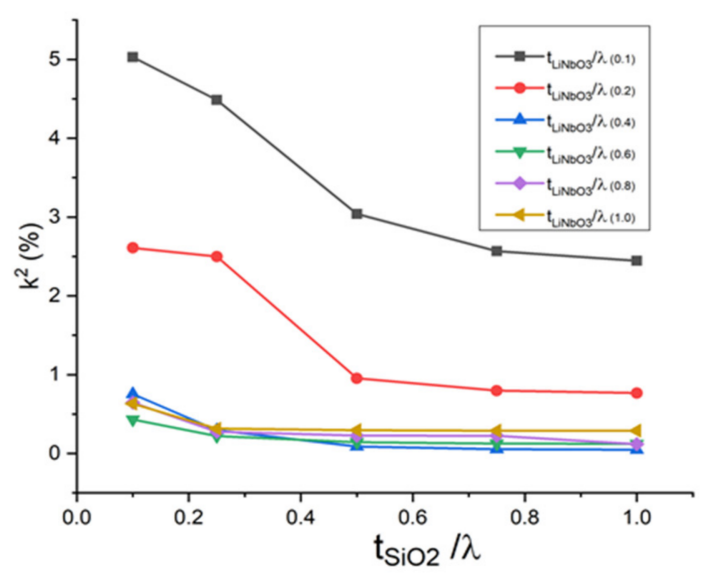

(b)

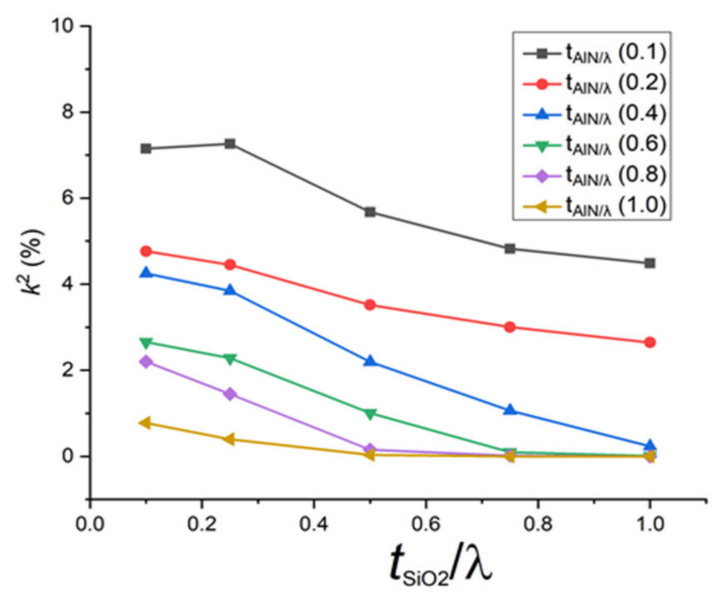

(c)

Figure 8. Electromechanical coupling coefficient $\left(k^{2}\right)$ versus normalised thickness of $\mathrm{SiO}_{2}$ on different normalised thicknesses of (a) $\mathrm{ZnO}(\mathbf{b}) \mathrm{LiNbO}_{3}$ (c) AlN.

Table 4. AOFM, acoustic phase velocity and $k^{2}$ of structures $\mathrm{A}, \mathrm{B}$ and $\mathrm{C}$ (with thickness $0.4 \mu \mathrm{m}$ for $\mathrm{SiO}_{2}, \mathrm{ZnO}, \mathrm{LiNbO}_{3}$, and AlN layer).

\begin{tabular}{ccccc}
\hline & Structure & Figure of Merit $\left(\mathbf{s}^{\mathbf{3}} / \mathbf{k g}\right)$ & Phase Velocity $(\mathrm{m} / \mathbf{s})$ & Electromechanical Coupling Coefficient \\
\hline $\mathbf{A}$ & $\mathrm{ZnO} / \mathrm{SiO}_{2} / \mathrm{Si}$ & $1.23 \times 10^{-14}$ & $3.63 \times 10^{3}$ & 4.20 \\
$\mathbf{B}$ & $\mathrm{LiNbO}_{3} / \mathrm{SiO}_{2} / \mathrm{Si}$ & $5.09 \times 10^{-14}$ & $3.83 \times 10^{3}$ & 5.03 \\
$\mathbf{C}$ & $\mathrm{AlN} / \mathrm{SiO}_{2} / \mathrm{Si}$ & $7.04 \times 10^{-14}$ & $4.42 \times 10^{3}$ & 7.15 \\
\hline
\end{tabular}

\section{Conclusions}

The study undertaken was targeted towards studying various CMOS compatible multilayer structures that would produce better acousto-optic figures of merit for an AOTF application. SAW propagation characteristics were investigated in three multilayer structures: $\mathrm{ZnO} / \mathrm{SiO}_{2} / \mathrm{Si}, \mathrm{LiNbO}_{3} / \mathrm{SiO}_{2} / \mathrm{Si}$, and $\mathrm{AlN} / \mathrm{SiO}_{2} / \mathrm{Si}$. It is found that the $\mathrm{AlN} / \mathrm{SiO}_{2} / \mathrm{Si}$ multilayer structure gave the highest electromechanical coupling coefficient, i.e., 7.15 at the normalised thickness of $0.1 \lambda$ (for $\mathrm{SiO}_{2}$ and AlN layer). It also has the highest acousto-optic figure of merit, i.e., $7.04 \times 10^{-14} \mathrm{~s}^{3} / \mathrm{kg}$ (which is also higher than the AOFM of individual bulk materials found in literature and mentioned in Table 3). Hence, it is concluded that by using an $\mathrm{AlN} / \mathrm{SiO} 2 / \mathrm{Si}$ multilayer structure, a high acousto-optic figure of merit can be achieved, which is not possible by using any choice of single bulk material. Moreover, 
it makes it possible to realise lab-on-chip applications using structure $\mathrm{C}\left(\mathrm{AlN} / \mathrm{SiO}_{2} / \mathrm{Si}\right)$, which is a CMOS compatible SAW structure.

Author Contributions: The work given here was primarily conducted by M.H. under the guidance of V.J., S.Q. and M.R.A.; M.H. contributed to the device design and multiphysics simulation. S.Q. and M.Z.A. gave helpful recommendations to the research.; conceptualisation, V.J. and M.H.; methodology, M.H., S.Q. and V.J.; software, M.H., S.Q. and M.Z.A.; validation, S.Q., V.J., M.R.A. and G.S.; formal analysis, V.J. and M.H.; investigation, M.H.; writing—original draft preparation, M.H.; writingreview and editing, M.R.A., V.J. and G.S.; supervision, M.R.A. and V.J.; All authors have read and agreed to the published version of the manuscript.

Funding: This research was funded by the European Union's Horizon 2020 research and innovation programme under grant agreement No. 854194.

Institutional Review Board Statement: Not applicable.

Informed Consent Statement: Not applicable.

Data Availability Statement: Not applicable.

Acknowledgments: This study was financially supported by the Postgraduate Studies programme of the Universiti Teknologi PETRONAS, Malaysia, and also the funding received from the European Union's Horizon 2020 research and innovation programme under grant agreement No. 854194. The authors would also like to further acknowledge Annas-ul-Hassan Qureshi, Muhammad Wahyu Nugraha, Muhammad Hamza Azam and Danish Mahmood Khan for their reviewing contribution.

Conflicts of Interest: The authors declare no conflict of interest.

\section{References}

1. Washburn, A.L.; Bailey, R.C. Photonics-on-a-chip: Recent advances in integrated waveguides as enabling detection elements for real-world, lab-on-a-chip biosensing applications. Analyst 2011, 136, 227-236. [CrossRef] [PubMed]

2. Hänsel, A.; Heck, M.J. Opportunities for photonic integrated circuits in optical gas sensors. J. Phys. Photonics 2020, 2, 012002. [CrossRef]

3. Zinoviev, K.; Carrascosa, L.G.; Sánchez del Río, J.; Sepulveda, B.; Domínguez, C.; Lechuga, L.M. Silicon photonic biosensors for lab-on-a-chip applications. Adv. Opt. Technol. 2008, 2008, 1-6. [CrossRef]

4. Zhu, H.; Goi, K.; Ishikura, N.; Omichi, K. Silicon Photonics Based System-On-Chip Gas Sensor. In Proceedings of the Optical Fiber Sensors, Zurich, Switzerland, 2-5 July 2018; Optical Society of America: Washington, DC, USA, 2018; p. ThE46.

5. Micó, G.; Gargallo, B.; Pastor, D.; Muñoz, P. Integrated optic sensing spectrometer: Concept and design. Sensors 2019, 19, 1018. [CrossRef] [PubMed]

6. Munk, D.; Katzman, M.; Hen, M.; Priel, M.; Feldberg, M.; Sharabani, T.; Levy, S.; Bergman, A.; Zadok, A. Surface acoustic wave photonic devices in silicon on insulator. Nat. Commun. 2019, 10, 4214. [CrossRef] [PubMed]

7. Poveda, A.C.; Bühler, D.D.; Sáez, A.C.; Santos, P.V.; Lima, M.M.d., Jr. Optical waveguide devices modulated by surface acoustic waves. arXiv 2018, arXiv:1811.03051. [CrossRef]

8. Van Der Slot, P.J.; Porcel, M.A.; Boller, K.-J. Surface acoustic waves for acousto-optic modulation in buried silicon nitride waveguides. Opt. Express 2019, 27, 1433-1452. [CrossRef] [PubMed]

9. Li, J.; Gui, Y.; Xu, R.; Zhang, Z.; Liu, W.; Lv, G.; Wang, M.; Li, C.; He, Z. Applications of AOTF Spectrometers in In Situ Lunar Measurements. Materials 2021, 14, 3454. [CrossRef]

10. Yang, Z.; Albrow-Owen, T.; Cai, W.; Hasan, T. Miniaturization of optical spectrometers. Science 2021, 371. [CrossRef] [PubMed]

11. Govindaraj, R.; Ganesh, G. Development and integration of an AOTF based NIR spectrophotometer. J. Opt. 2018, 47, 132-142. [CrossRef]

12. Fernandes, M.E. Acousto-Optic Effect and Its Use in Signal Processing. Available online: https://www.semanticscholar. org/paper/Acousto-Optic-Effect-and-Its-use-in-Signal-Fernandes/9ce8b3947de1e06d1f7e83066244098cf10145b6 (accessed on 21 November 2021).

13. Honardoost, A. Thin-Film Lithium Niobate Integrated Photonics on Silicon for Electro-and Nonlinear-Optic Applications. Ph.D. Thesis, University of Central Florida, Orlando, FL, USA, May 2020.

14. Muralt, P.; Polcawich, R.G.; Trolier-McKinstry, S. Piezoelectric thin films for sensors, actuators, and energy harvesting. MRS Bull. 2009, 34, 658-664. [CrossRef]

15. Meillaud, F.; Boccard, M.; Bugnon, G.; Despeisse, M.; Hänni, S.; Haug, F.-J.; Persoz, J.; Schüttauf, J.-W.; Stuckelberger, M.; Ballif, C. Recent advances and remaining challenges in thin-film silicon photovoltaic technology. Mater. Today 2015, 18, 378-384. [CrossRef]

16. Dharmadasa, I. Advances in Thin-Film Solar Cells; Jenny Stanford Publishing: Singapore, 2018.

17. Melville, O.A.; Lessard, B.H.; Bender, T.P. Phthalocyanine-based organic thin-film transistors: A review of recent advances. ACS Appl. Mater. Interfaces 2015, 7, 13105-13118. [CrossRef] 
18. Fortunato, E.; Barquinha, P.; Martins, R. Oxide semiconductor thin-film transistors: A review of recent advances. Adv. Mater. 2012, 24, 2945-2986. [CrossRef]

19. Fu, Y.Q.; Luo, J.; Nguyen, N.-T.; Walton, A.; Flewitt, A.J.; Zu, X.-T.; Li, Y.; McHale, G.; Matthews, A.; Iborra, E. Advances in piezoelectric thin films for acoustic biosensors, acoustofluidics and lab-on-chip applications. Prog. Mater. Sci. 2017, 89, 31-91. [CrossRef]

20. Juneau, J.-M. The Simulation, Design, and Fabrication of Optical Filters; Rose Hulman Institute of Technology: Terre Haute, IN, USA, 2017.

21. Keshmiri, S.; Mirsalehi, M. Multilayer Thin-Film Optical Filters: Design, Fabrication, and Applications. In Physics and Technology of Thin Films: IWTF 2003; World Scientific: Singapore, 2004; pp. 306-317.

22. Kalantar-Zadeh, K.; Powell, D.A.; Wlodarski, W.; Ippolito, S.; Galatsis, K. Comparison of layered based SAW sensors. Sens. Actuators B Chem. 2003, 91, 303-308. [CrossRef]

23. Chang, I. Tunable acousto-optic filters: An overview. In Proceedings of the Acousto-Optics: Device Development/Instrumentation/ Applications, San Diego, CA, USA, 26-27 August 1976; International Society for Optics and Photonics: Bellingham, DC, USA, 1976; pp. 12-22.

24. Mantsevich, S.; Korablev, O.; Kalinnikov, Y.K.; Ivanov, A.Y.; Kiselev, A. Wide-aperture $\mathrm{TeO}_{2}$ AOTF at low temperatures: Operation and survival. Ultrasonics 2015, 59, 50-58. [CrossRef] [PubMed]

25. Georgiev, G.; Glenar, D.A.; Hillman, J.J. Spectral characterization of acousto-optic filters used in imaging spectroscopy. Appl. Opt. 2002, 41, 209-217. [CrossRef]

26. Mukhopadhyay, T.; Mahata, A.; Adhikari, S.; Zaeem, M.A. Effective mechanical properties of multilayer nano-heterostructures. Sci. Rep. 2017, 7, 15818. [CrossRef] [PubMed]

27. Pfeiffer, J.B.; Wagner, K.H. Acousto-optic figure of merit search. Phys. Procedia 2015, 70, 762-765. [CrossRef]

28. Yu, C.; Yu, X.-X.; Zheng, D.-S.; Yin, H. Piezoelectric potential enhanced photocatalytic performance based on ZnO with different nanostructures. Nanotechnology 2021, 32, 135703. [CrossRef] [PubMed]

29. Yang, A.; Qiu, Y.; Yang, D.; Lin, K.; Guo, S. Piezoelectric property comparison of two-dimensional ZnO nanostructures for energy harvesting devices. RSC Adv. 2021, 11, 3363-3370. [CrossRef]

30. Weis, R.; Gaylord, T. Lithium niobate: Summary of physical properties and crystal structure. Appl. Phys. A 1985, 37, 191-203. [CrossRef]

31. Kaletta, U.C.; Wipf, C.; Fraschke, M.; Wolansky, D.; Schubert, M.A.; Schroeder, T.; Wenger, C. AlN $/ \mathrm{SiO}_{2} / \mathrm{Si}_{3} \mathrm{~N}_{4} / \mathrm{Si}_{(100)-b a s e d}$ CMOS compatible surface acoustic wave filter with-12.8-dB minimum insertion loss. IEEE Trans. Electron Devices 2015, 62, 764-768. [CrossRef]

32. Kaletta, U.C.; Wenger, C. FEM simulation of Rayleigh waves for CMOS compatible SAW devices based on $\mathrm{AlN} / \mathrm{SiO} 2 / \mathrm{Si}(100)$. Ultrasonics 2014, 54, 291-295. [CrossRef] [PubMed]

33. Aslam, M.Z.; Jeoti, V.; Karuppanan, S.; Malik, A.F.; Iqbal, A. FEM analysis of sezawa mode SAW sensor for VOC based on CMOS compatible $\mathrm{AlN} / \mathrm{SiO}_{2} / \mathrm{Si}$ multilayer structure. Sensors 2018, 18, 1687. [CrossRef] [PubMed]

34. Zhang, Z.; Wen, Z.; Wang, C. Investigation of surface acoustic waves propagating in $\mathrm{ZnO}-S i O_{2}-$ Si multilayer structure. Ultrasonics 2013, 53, 363-368. [CrossRef]

35. Shu, L.; Peng, B.; Li, C.; Gong, D.; Yang, Z.; Liu, X.; Zhang, W. The characterization of surface acoustic wave devices based on AlN-metal structures. Sensors 2016, 16, 526. [CrossRef] [PubMed]

36. Mohanan, A.A.; Islam, M.S.; Ali, S.H.M.; Parthiban, R.; Ramakrishnan, N. Investigation into mass loading sensitivity of sezawa wave mode-based surface acoustic wave sensors. Sensors 2013, 13, 2164-2175. [CrossRef]

37. Maouhoub, S.; Aoura, Y.; Mir, A. FEM simulation of AlN thin layers on diamond substrates for high frequency SAW devices. Diam. Relat. Mater. 2016, 62,7-13. [CrossRef]

38. Hofer, M.; Finger, N.; Kovacs, G.; Schoberl, J.; Langer, U.; Lerch, R. Finite element simulation of bulk-and surface acoustic wave (SAW) interaction in SAW devices. In Proceedings of the 2002 IEEE Ultrasonics Symposium, Munich, Germany, 8-11 October 2002; pp. 53-56.

39. Buchner, M.; Ruile, W.; Dietz, A.; Dill, R. FEM analysis of the reflection coefficient of SAWs in an infinite periodic array. In Proceedings of the IEEE 1991 Ultrasonics Symposium, Orlando, FL, USA, 8-11 December 1991; pp. 371-375.

40. Yong, Y.-K. Analysis of periodic structures for BAW and SAW resonators. In Proceedings of the 2001 IEEE Ultrasonics Symposium. Proceedings. An International Symposium (Cat. No. 01CH37263), Atlanta, GA, USA, 7-10 October 2001; pp. 781-790.

41. McIntosh, R.; Bhalla, A.S.; Guo, R. Finite element modeling of acousto-optic effect and optimization of the figure of merit. In Proceedings of the Photonic Fiber and Crystal Devices: Advances in Materials and Innovations in Device Applications VI, San Diego, CA, USA, 12-13 August 2021; p. 849703. [CrossRef]

42. Davydov, S.Y. Evaluation of physical parameters for the group III nitrates: BN, AlN, GaN, and InN. Semiconductors 2002, 36, 41-44. [CrossRef]

43. Aslam, M.Z.; Jeoti, V.; Karuppanan, S.; Malik, A.F. FEM Simulation Analysis of AlN/SiO 2/Si Multilayer Structure and Effect of IDT Configuration on SAW Propagation Modes and Characteristics. In Proceedings of the 2018 International Conference on Intelligent and Advanced System (ICIAS), Kuala Lumpur, Malaysia, 13-14 August 2018; pp. 1-4.

44. Malik, A.F.; Jeoti, V.; Fawzy, M.; Iqbal, A.; Aslam, Z.; Pandian, M.S.; Marigo, E. Estimation of SAW velocity and coupling coefficient in multilayered piezo-substrates $\mathrm{AlN} / \mathrm{SiO}_{2} / \mathrm{Si}$. In Proceedings of the 2016 6th International Conference on Intelligent and Advanced Systems (ICIAS), Kuala Lumpur, Malaysia, 15-17 August 2016; pp. 1-5. 
45. Jain, S.; Mansingh, A. Thin film layered structure for acousto-optic devices. J. Phys. D Appl. Phys. 1992, 25, 1116. [CrossRef]

46. Nayak, R.; Nayak, A.; Gupta, V.; Sreenivas, K. Optical interactions in ZnO-TeO/sub 2/bi-layer for AO device applications. In Proceedings of the IEEE Symposium on Ultrasonics 2003, Honolulu, HI, USA, 5-8 October 2003; pp. 1129-1132.

47. Stedham, C.; Draper, M.; Ward, J.; Wachman, E.; Pannell, C. A novel acousto-optic tunable filter for use in hyperspectral imaging systems. In Proceedings of the Physics and Simulation of Optoelectronic Devices XVI, San Jose, CA, USA, 22 February 2008; p. 68891.

48. Kitui, M.; Mwamburi, M.M.; Gaitho, F.; Maghanga, C.M. Optical Properties of TiO2 Based Multilayer Thin Films: Application to Optical Filters. Int. J. Thin Film Sci. Technol. 2015, 4, 1.

49. Maouhoub, S.; Aoura, Y.; Mir, A. FEM simulation of Rayleigh waves for SAW devices based on ZnO/AlN/Si. Microelectron. Eng. 2015, 136, 22-25. [CrossRef]

50. Mahmood, T.; Cao, C.; Khan, W.S.; Usman, Z.; Butt, F.K.; Hussain, S. Electronic, elastic, optical properties of rutile TiO 2 under pressure: A DFT study. Phys. B Condens. Matter 2012, 407, 958-965. [CrossRef]

51. Rathore, B.P.S.; Prakash, R.; Kaur, D. Effect of AlN layer on the resistive switching properties of $\mathrm{TiO}_{2}$ based ReRAM memory devices. Curr. Appl. Phys. 2018, 18, 102-106. [CrossRef]

52. Yoshida, F.; Nagashima, K.; Tsubouchi, M.; Maruyama, M.; Ochi, Y. THz pulse generation using a contact grating device composed of $\mathrm{TiO}_{2} / \mathrm{SiO}_{2}$ thin films on LiNbO3 crystal. J. Appl. Phys. 2016, 120, 183103. [CrossRef]

53. Hao, L.; Li, Y.; Zhu, J.; Wu, Z.; Long, F.; Liu, X.; Zhang, W. Microstructure and memory characteristics of ferroelectric LiNbO3/ZnO composite thin films on $\mathrm{Pt} / \mathrm{TiO}_{2} / \mathrm{SiO}_{2} / \mathrm{Si}$ substrates. J. Alloy. Compd. 2014, 590, 205-209. [CrossRef]

54. Shirazi, M.; Hosseinnejad, M.; Zendehnam, A.; Ghorannevis, Z.; Ghoranneviss, M. Deposition of ZnO multilayer on LiNbO3 single crystals by DC-magnetron sputtering. Appl. Surf. Sci. 2011, 257, 10233-10238. [CrossRef]

55. Xiong, S.; Liu, X.; Zhou, J.; Liu, Y.; Shen, Y.; Yin, X.; Wu, J.; Tao, R.; Fu, Y.; Duan, H. Stability studies of ZnO and AlN thin film acoustic wave devices in acid and alkali harsh environments. RSC Adv. 2020, 10, 19178-19184. [CrossRef]

56. Kischkat, J.; Peters, S.; Gruska, B.; Semtsiv, M.; Chashnikova, M.; Klinkmüller, M.; Fedosenko, O.; Machulik, S.; Aleksandrova, A.; Monastyrskyi, G. Mid-infrared optical properties of thin films of aluminum oxide, titanium dioxide, silicon dioxide, aluminum nitride, and silicon nitride. Appl. Opt. 2012, 51, 6789-6798. [CrossRef] [PubMed]

57. Newnham, R.E. Properties of Materials: Anisotropy, Symmetry, Structure; Oxford University Press on Demand: Oxford, UK, 2005.

58. Benetti, M.; Cannata, D.; Di Pictrantonio, F.; Verona, E. Growth of AlN piezoelectric film on diamond for high-frequency surface acoustic wave devices. IEEE Trans. Ultrason. Ferroelectr. Freq. Control 2005, 52, 1806-1811. [CrossRef] [PubMed]

59. Takagaki, Y.; Santos, P.; Wiebicke, E.; Brandt, O.; Schönherr, H.-P.; Ploog, K. Superhigh-frequency surface-acoustic-wave transducers using AlN layers grown on SiC substrates. Appl. Phys. Lett. 2002, 81, 2538-2540. [CrossRef]

60. Bu, G.; Ciplys, D.; Shur, M.; Schowalter, L.J.; Schujman, S.; Gaska, R. Surface acoustic wave velocity in single-crystal AlN substrates. IEEE Trans. Ultrason. Ferroelectr. Freq. Control 2006, 53, 251-254. [CrossRef] [PubMed] 